\title{
Aromatic Compound-Dependent Staphylococcus aureus Is Safe in a Nasal Colonization Leukopenic Murine Model
}

\author{
María S. Barbagelata, ${ }^{1,2}$ Lucía P. Alvarez, ${ }^{1,2}$ Cristian M. Dotto, ${ }^{1}$ \\ Santiago M. Lattar, ${ }^{1,2}$ Daniel O. Sordelli, ${ }^{1,2}$ and Fernanda R. Buzzola ${ }^{1,2}$ \\ ${ }^{1}$ Departamento de Microbiología, Parasitología e Inmunología, Facultad de Medicina, Universidad de Buenos Aires, \\ C1121ABG Buenos Aires, Argentina \\ ${ }^{2}$ Instituto de Microbiología y Parasitología Médica, Facultad de Medicina, Universidad de Buenos Aires-Consejo Nacional de \\ Investigaciones Científicas y Tecnológicas (IMPaM, UBA-CONICET), Paraguay 2155, Piso 12, C1121ABG Buenos Aires, Argentina
}

Correspondence should be addressed to Fernanda R. Buzzola, ferbuzzola@yahoo.com

Received 20 March 2012; Revised 28 June 2012; Accepted 28 June 2012

Academic Editor: Todd R. Callaway

Copyright ( $) 2012$ María S. Barbagelata et al. This is an open access article distributed under the Creative Commons Attribution License, which permits unrestricted use, distribution, and reproduction in any medium, provided the original work is properly cited.

Staphylococcus aureus nasal carriage is a risk factor for individuals suffering from trauma, surgical procedures, invasive devices, and/ or decreased immunity. Recently, we demonstrated that artificial nasal colonization with an attenuated S. aureus mutant reduced by bacterial interference with the colonization of pathogenic strains of $S$. aureus. This could be an optional tool to diminish the rate of $S$. aureus infections in hospitalized patients. The aim of this study was to construct a safe $\triangle a r o A$ mutant of $S$. aureus and to discriminate it from nasal colonizing and osteomyelitis $S$. aureus isolates by SmaI pulsed-field gel electrophoresis (PFGE) typing. The $\triangle$ aro $A$ mutant, named $\mathrm{RD} 17$, exhibited an $\mathrm{LD}_{50}\left(3.2 \times 10^{6}\right.$ colony-forming unit (CFU) significantly higher than that of the parental strain $\left(2.2 \times 10^{3} \mathrm{CFU}\right)$. The colony number of the RD17 mutants recovered from nares of leukopenic mice was similar to that observed in the animals of the control group. Therefore, the $\triangle a r o A$ mutant was demonstrated to be safe due to maintaining low growth levels in the nares regardless of immune status of the animals. PFGE typing allowed the unequivocal identification of the S. aureus and differentiation of aroA mutants in nasal colonizing and osteomyelitis isolates. This information could be important to discriminate endogenous infections from laboratory strains of $S$. aureus.

\section{Introduction}

Staphylococcus aureus is part of the human microbiota and remains one of the most important community and nosocomial-acquired pathogens, with high rates of hospital-associated infections [1]. Although multiple body sites can be colonized, the anterior nares of the nose is the most common site of colonization [2]. Its prevalence in a healthy human population is around 30\% [3]. Carriers of methicillinresistant S. aureus (MRSA) have a higher risk of infection than those colonized by methicillin-sensitive (MSSA) strains $[4,5]$. It has been demonstrated that most MRSA infections following initial colonization or infection are caused by identical strains [6].

Bloodstream infections are an important cause of morbidity and mortality during immunosuppressive conditions (diabetes mellitus, liver diseases, renal failure, corticotherapy, haemodialysis treatment, etc.), particularly for $S$. aureus nasal carriers $[7,8]$. This susceptibility appears to be directly related to the severity and length of leukopenia [9]. Leukocytes, mainly neutrophils, are the main source of proinflammatory mediators and are essential for resistance to bacterial infections $[10,11]$.

Using a murine model of nasal colonization we demonstrated, recently, that an auxotrophic S. aureus mutant (named NK41) was able to interfere with the colonization of MRSA isolates belonging to Cordobes and Pediatric clones [12]. The auxotrophy of S. aureus NK41 mutant was achieved by insertion of a kanamycin resistance $\left(\mathrm{Ka}^{R}\right)$ gene into the aroA gene, which encodes the enzyme 5-enolpyruvylshikimate 3-phosphate synthase (EPSPS). The EPSPS is part of the metabolic pathway of aromatic amino acids; 
therefore, bacteria with mutations in the initial steps of this metabolic pathway are auxotrophic to aromatic amino acids [13]. Herein, we constructed a $\triangle a r o A$ mutant of $S$. aureus, and its safety was determined by nasal colonization of leukopenic mice. We also differentiated the $\triangle a r o A$ (RD17) and $\operatorname{aro} A:: \mathrm{Ka}^{R}$ (NK41) mutants from nasal colonizing and osteomyelitis $S$. aureus isolates by pulsed field gel electrophoresis (PFGE) pattern. This additional knowledge is important to develop alternative strategies for the prevention of staphylococcal diseases.

\section{Material and Methods}

2.1. Bacterial Strain and Growth Conditions. Bacterial reference strains and plasmids and $S$. aureus attenuated mutants used in the present study are described in Table 1. Sixtytwo single S. aureus isolates were obtained from 258 nasal swabs as a standard prophylactic procedure in patients at the time of admission to two hospitals of Buenos Aires City during the period 2009-2010. Also individual S. aureus isolates were obtained from 97 patients with osteomyelitis from seven hospitals in Argentina (four in Buenos Aires City, two in Buenos Aires Province, and one in the City of Santa $\mathrm{Fe}$ ). Isolation and identification of $S$. aureus were performed according to routine culture procedures used in the Clinical Bacteriology laboratory [14]. Subcultures of single colonies of homogeneous size and pigmentation from primary isolation on blood agar plates (Britania, Buenos Aires, Argentina) were frozen in brain heart infusion (BHI) (Britania) broth with $20 \%$ glycerol (Promega, Madison, USA) at $-20^{\circ} \mathrm{C}$ until further use. Species identification was confirmed by polymerase chain reaction (PCR) amplification of S. aureus-specific sequences according to Martineau et al. [15]. S. aureus isolates were tested for susceptibility to methicillin (oxacillin $1 \mu \mathrm{g}$ ) (Britania) using the agar diffusion method according to the Clinical and Laboratory Standards Institute (CLSI) recommendations [16] and confirmed by PCR of mecA gene as performed by Fey et al. [17]. Escherichia coli strains were grown in LuriaBertani (LB) medium (Britania) supplemented with ampicillin (Amp) (50 or $100 \mu \mathrm{g} / \mathrm{mL}$ ) (Sigma Chemical Co., St. Louis, USA), isopropyl- $\beta$-D-thiogalactopyranoside (IPTG) $(0.5 \mathrm{mM})$ (Promega), and 5-bromo-4-chloro-3-indolyl- $\beta$ D-galactopyranoside (X-Gal) $(20 \mathrm{mg} / \mathrm{mL})$ (Promega) as needed for maintenance of plasmids. For selection of chromosomal markers or maintenance of plasmids, S. aureus antibiotic concentrations were the following: chloramphenicol $(\mathrm{Cm}) 10 \mu \mathrm{g} / \mathrm{mL}$ (Sigma Chemical Co.), erythromycin (Em) $5 \mu \mathrm{g} / \mathrm{mL}$ (Sigma Chemical Co.), and X-Gal, $40 \mathrm{mg} / \mathrm{mL}$. For phenotype characterization assays, colonies were replicated onto defined minimum medium (DMM) agar plates for S. aureus as described by Pattee and Neveln [18]. Briefly, DMM agar plates were supplemented with the aromatic amino acids tryptophan $(\operatorname{Trp})(0.05 \mathrm{mM})$, phenylalanine (Phe) $(0.24 \mathrm{mM})$, and tyrosine (Tyr) $(0.28 \mathrm{mM})$, as well as the precursors $p$-aminobenzoic acid (PABA) $(0.05 \mathrm{mg} / \mathrm{L})$ and 2,3-dihydroxybenzoic acid (DHB) $(10 \mathrm{mg} / \mathrm{L})$. All reactives utilized to prepare the DMM agar plates were purchased from Sigma Chemical Co. An aro mutant proliferates only in minimal medium supplemented with the three aromatic amino acids and PABA and DHB.

2.2. Generation of Deletion aroA Mutant. To obtain S. aureus $\triangle a r o A$ mutant, four primers were designed (Table 2) that amplified two fragments of 625 and $980 \mathrm{bp}$ that flanked the sequences of the aroA gene to the left (primers Aro-A and Aro-B) and the right (primers Aro-C and Aro-D), respectively. Primer Aro-C has a 16-base complementary region with primer Aro-B to allow the products of the first PCR anneal. A second PCR was performed with primers Aro-A and Aro-D to obtain a single fragment using the first PCR products as template. Then, $1 \mu \mathrm{L}$ of each of the first PCR products was mixed with $10 \mathrm{pmol}$ of the outside primers and amplified by PCR. The fusion product $(\sim 1.6 \mathrm{~kb})$ was purified and cloned in the pGEM-T Easy Vector (Promega). The plasmid was digested with BamHI and SalI (Promega) to purify the cloned fragment, and, finally, the fragment was fused by ligation into the shuttle plasmid pMAD (to yield pMAD-DEL). Blue and $\mathrm{Amp}^{R}$ colonies were selected on LB plates complemented with Amp and X-Gal. Plasmids were obtained from the selected transformants to verify by PCR the loss of the $650 \mathrm{bp}$ fragment from the aro $A$ gene yielding a $1.6 \mathrm{~kb}$ deletion fragment. This construction was named pMAD-DEL. The resulting plasmid was electropored into RN4220 S. aureus to generate transformants. Electrocompetent RN6390 was subsequently transformed with pMADDEL isolated from RN4220. pMAD contains a temperaturesensitive origin of replication and an Em resistance gene in gram-positive strains [19]. Homologous recombination experiments were performed as previously described [20]. RN6390 S. aureus strains with the desired fragment of PCR product were replicated onto DMM agar plates [18] supplemented or not with Trp, Phe, Tyr, PABA, and DHB to check the aromatic amino acid auxotrophic phenotype.

2.3. Complementation. A $1.4 \mathrm{~kb}$ fragment encompassing the aroA gene from S. aureus RN6390 was amplified by PCR using primers $\mathrm{Fw}$-aroComp and $\mathrm{Rv}$-aroComp (Table 2). The PCR fragment was restricted and ligated into vector pALC1743 (kindly provided by A. L. Cheung) after deletion of the $g f p$ gene and then transformed into E. coli DH5 $\alpha$ (Invitrogen, Carlsbad, CA) [21]. Restriction analysis and DNA sequencing confirmed the orientation and authenticity of the cloned gene. The recombinant plasmid was electroporated into the $\triangle$ aroA RN6390 S. aureus mutant (RD17), and Cmresistant colonies were selected. Transformants were tested for restoration of the wild-type phenotype.

2.4. Determination of the Bacterial Virulence in Mice. CF-1 outbred mice were bred and maintained in the vivarium of the Department of Microbiology, School of Medicine, University of Buenos Aires in accordance with the guidelines set forth by the US National Institutes of Health [22]. For $50 \%$ lethal dose $\left(\mathrm{LD}_{50}\right)$ studies, 6-week-old male $\mathrm{CF}-1$ mice were injected intraperitoneally with $0.5 \mathrm{~mL}$ of a suspension 
TABLE 1: Bacterial strains and plasmids used in this study.

\begin{tabular}{|c|c|c|}
\hline Strain or plasmid & Comment & Source \\
\hline RN4220 & Mutant strain of Staph. aureus 8325-4 that accepts foreign DNA & \\
\hline RN6390 & $\begin{array}{l}a g r^{+} \text {laboratory strain related to } 8325-4 \text {, maintains haemolytic pattern when propagated on sheep } \\
\text { erythrocytes }\end{array}$ & \\
\hline Newman & S. aureus polysaccharide capsular serotype 5 (CP5) & \\
\hline NK41 & Newman aroA::Ka ${ }^{R}$ & \\
\hline RD17; RD89 & RN6390 $\triangle a r o A$ & This study \\
\hline $\mathrm{DH} 5 \alpha$ & E. coli host cloning vectors & Invitrogen \\
\hline pMAD & E. coli-S.aureus (Listeria) shuttle vector with the $b g a B$ gene encoding a $\beta$-galactosidase. $A m p^{R} / \mathrm{Em}^{R}$ & \\
\hline pMAD-DEL & pMAD plasmid containing the mutant allele for deletion of the aro $A$ gene & This study \\
\hline pGEM-T Easy & $\mathrm{Amp}^{R}$, lac $Z^{\prime}, \mathrm{fl}$ ori, $\mathrm{MCS}, \mathrm{Mob}^{-}$, cloning T vector & Promega \\
\hline$\underline{\mathrm{pALC} 1743}$ & pSK236 ( $g f p_{u v r}$ with $a g r$ P3 promoter) & \\
\hline
\end{tabular}

TABle 2: Primers used in this study.

\begin{tabular}{ll}
\hline Name & Sequence $^{\mathrm{a}}$ \\
\hline Fw-aroComp & $5^{\prime}$-CTCTCTAGAACATTACAACATGCATGTGAAC-3' \\
Rv-aroComp & $5^{\prime}$-ACGCGTCGACTGCGTCATCGTTGTCAGTAGT-3' \\
Aro-A & $5^{\prime}$-CTCGGATCCACATTACAACATGCATGTGAAC-3' \\
Aro-B & $5^{\prime}$-TAATGATGGTCGGTTCCTT-3' \\
Aro-C & $5^{\prime}$-TTCTAAGGAACCGACCATCAGCGAGCCTGTCAAAATCAA-3' \\
Aro-D & $5^{\prime}$-ACGCGTCGACCATCGCCGTGTTCTATTTCC-3' \\
\hline
\end{tabular}

anzyme restriction sites are underlined; TCTAGA: XbaI, GTCGAC: SalI, GGATCC: BamHI.

ranging from $10^{1}$ to $10^{9} \mathrm{CFU}$ of bacterial strain and $2 \%(\mathrm{w} / \mathrm{v})$ Brewer's yeast (Sigma Chemical Co.) in BHI broth [23]. Three groups, each comprising 10 mice, from three separate tests received serial log dilutions of each bacterial strain. The estimation of the $\mathrm{LD}_{50}$ was made after 7 days using a software for probit analysis (PASW 18, IBM Software, Inc.) [24].

2.5. Nasal Colonization in Leukopenic Murine Model. CF-1 female mice weighing 27 to $32 \mathrm{~g}$ were used for the experiments. Mice were rendered leukopenic by injecting cyclophosphamide (Sigma Chemical Co.) (200 mg/kg/day) on days 4 and 2 before challenge. Previous studies have shown that this regimen produces leukopenia in this model for 5 days [25]. At time 0, groups of 10-15 mice were challenged by the intranasal route with $10 \mu \mathrm{L}$ of suspension containing approximately $10^{7} \mathrm{CFU}$ of the RD17 ( $\triangle$ aroA mutant) or Sa14 (MRSA isolate). To evaluate nares colonization, mice were $\mathrm{CO}_{2}$-euthanized 24 hours after bacterial challenge and cultures were made from their nasal tissues. The area around the nasal region was wiped with $70 \%$ ethanol, and the nose was excised and homogenized in $400 \mathrm{~mL}$ tryptic soy broth (TSB) (Britania) using a tissue grinder. The lungs also were excised and homogenized separately in $2 \mathrm{~mL}$ of sterile distilled water. Tenfold serial dilutions of the tissue homogenates and blood samples were plated onto tryptic soy agar (TSA) (Britania) plates. Animals not treated with cyclophosphamide, but challenged under the conditions as the leukopenic mice, were used for control.

2.6. Pulsed-Field Gel Electrophoresis (PFGE) Typing. The clonality of the $S$. aureus clinical and nasal isolates, the $S$. aureus reference strains, and their derived attenuated mutants was assessed by PFGE of SmaI-digested (Promega) chromosomal DNA fragments [27] using a CHEF-DR II apparatus (BioRad Laboratories, CA, USA) as previously described [28]. Reference strains representative of the prevalent MRSA clones in Buenos Aires (Cordobes, Pediatric, and Brazilian, resp.), were included [26]. The similarity between PFGE types was evaluated by the Dice coefficient. The resultant similarity matrix was analyzed by the unweighted pair group method using arithmetic averages (UPGMA), and data were analyzed with the TREECON software for Windows [29].

2.7. Statistical Analysis. In order to obtain a statistical assessment of virulence for mice of the S. aureus RN6390 and RD17 mutants, the 7-day survival ratios from three separate tests were pooled for estimation of the $\mathrm{LD}_{50}$ by a computrrized program for probit analysis (PASW 18, IBM Software, Inc.). Nonparametrical data was analyzed with the Mann-Whitney test using the GraphPad Prism version 4.00 software for Windows. $P$ values lower than 0.05 were considered statistically significant. 


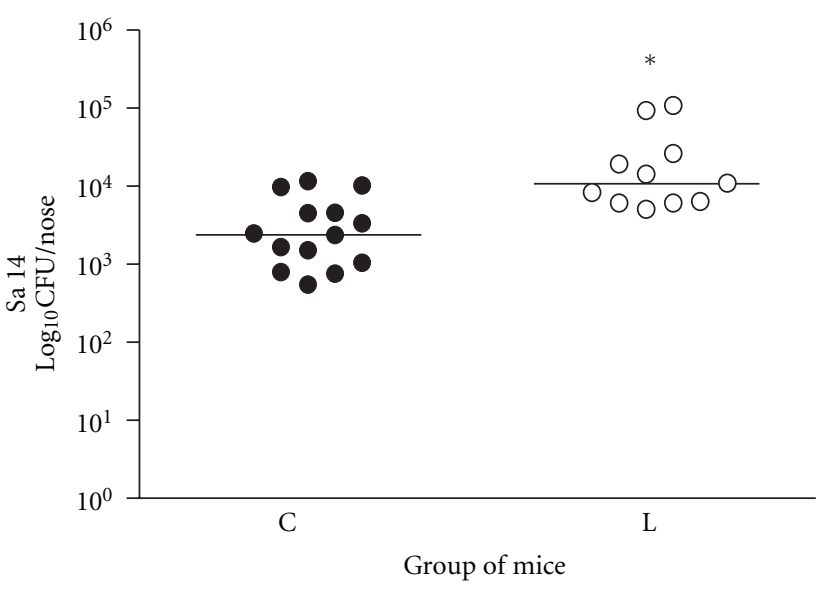

(a)

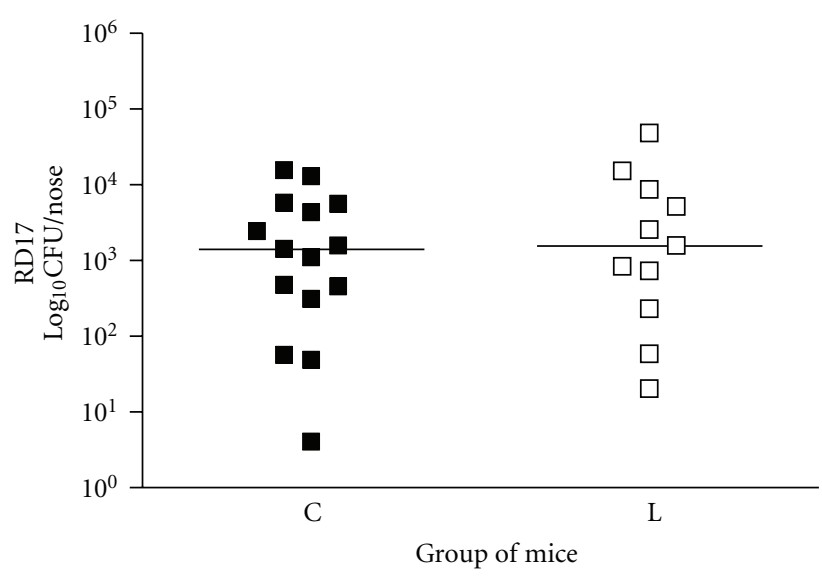

(b)

Figure 1: Nasal colonization in a mice leukopenic model. Groups of 10-15 leukopenic and control mice were inoculated intranasally with a suspension of $10^{7} \mathrm{CFU}$ of the Sa14 (panel a) isolate or RD17 (panel b) attenuated mutant. Challenged mice were sacrificed and their nose tissue cultured to determine CFU. The horizontal lines represent the median values. Panel (a) the leukopenic (L) mice showed a significant increase in the CFU number of the Sa14 isolate (median $=10800 \mathrm{CFU} /$ nose) compared with that of control group (C) (median $=2384 \mathrm{CFU} /$ nose). ${ }^{*} P<0.001$, Mann-Whitney test. Panel (b): animals inoculated with the RD17 mutant showed similar CFU number in the L group (median $=1552 \mathrm{CFU} /$ nose) as well as in the $\mathrm{C}$ group of mice (median $=1400 \mathrm{CFU} /$ nose). $P>0.05$, Mann-Whitney test.

\section{Results}

3.1. Characterization of RN6390 $\triangle$ aroA Mutant. After the analysis of 950 colonies, only 2 named RD17 and RD89 presented the loss of a $648 \mathrm{bp}$ fragment between the 659 and 2201 sites of the aroA gene yielding a $1.6 \mathrm{~kb}$ PCR product. Then, in order to characterize the auxotrophic phenotype, the isolated mutants were replicated onto DMM agar plates for $S$. aureus [18] with or without aromatic amino acids Trp, Phe, Tyr and its precursors PABA and DHB. The bacteria that failed to grow after 20 hours of incubation on DMM plates without addition of the three aromatic amino acids and PABA and DHB were considered Aro-deficient. Therefore, the deletion of the aroA gene encoding the EPSPS led to an aroA auxotrophy of the RD17 and RD89 mutants. Because the RD17 and RD89 mutants exhibited the same phenotype and genotype, subsequent experiments were performed only on RD17. Complementation assay restored the wild-type phenotype of the RD17 mutant. The growth rates of the $\triangle$ aro $A$ mutant and its parental strain RN6390 were similar in TSB medium (data not shown). In addition, RD17 mutant exhibited a very stable phenotype, since its reversion frequency performed as described previously was $<1 \times 10^{-12}$ [13].

To determine the attenuation of RD17 mutant in mice, the probit analysis comparing the $\mathrm{LD}_{50}$ with the $\triangle$ aro $A$ mutant and its parental strain was performed. The $\mathrm{LD}_{50}$ of the parental RN6390 strain $\left(2.2 \times 10^{3} \mathrm{CFU} \pm 95 \% \mathrm{CI}: 2.6 \times\right.$ $\left.10^{1}-8.5 \times 10^{3} \mathrm{CFU}\right)$ was statistically significant $(P<0.0001)$ different from the $\mathrm{LD}_{50}$ of the RD17 mutant $\left(3.2 \times 10^{6} \mathrm{CFU}\right.$ $\left.\pm 95 \% \mathrm{CI}: 1.6 \times 10^{6}-9.7 \times 10^{6} \mathrm{CFU}\right)$. This statistical increase in the $\mathrm{LD}_{50}$ of the RD17 mutant confirmed its attenuation in mice.
3.2. Nasal Colonization in Leukopenic Murine Model. The safety of the $\triangle a r o A$ mutant was evaluated using leukopenic mice model. To render the nasal colonization, the RD17 mutant and an epidemiologically unrelated MRSA nasal isolate (Sa14) were administrated into the nose of leukopenic groups of mice as we described previously [12]. CF-1 mice were treated with cyclophosphamide to render them leukopenic. Mice receiving cyclophosphamide had significantly lower white blood cells counts $(331 \pm 185$ cells $/ \mathrm{mL})$ than mice receiving the saline control $(3044 \pm 501$ cells $/ \mathrm{mL})$ $(P<0.0001)$. The number of Sa14 (MRSA) colonies recovered from the noses of leukopenic mice group was significant higher than that observed in the control group (Figure 1(a)); in contrast, the number of RD17 mutant colonies recovered was similar between the groups (Figure 1(b)). No bacteria was recovered from blood or lungs of neither the groups of mice (data not shown). Therefore, the RD17 mutant maintained low growth levels in the nose regardless of immune status of the animals.

3.3. Pulsed-Field Gel Electrophoresis (PFGE) Typing. All S. aureus osteomyelitis and nasal colonizing isolates $(n=159)$, the obtained mutants (RD17 and NK41), and their parental strains (RN6390 and Newman) were discriminated into 40 fingerprint groups by PFGE typing (Figure 2). A dendrogram that included all patterns was constructed on the basis of the levels of similarity, and a cut-off point of $80 \%$ was considered to define the groups. SmaI PFGE band analysis revealed the presence of six major pulsotypes (named 1, 4, 5, 10, 28, and 40) that included 86 isolates. The remainders were evenly distributed in 33 groups of one to five isolates and one group with 9 isolates. All mutants and their parental wildtype strains exhibited a markedly different macrorestriction 


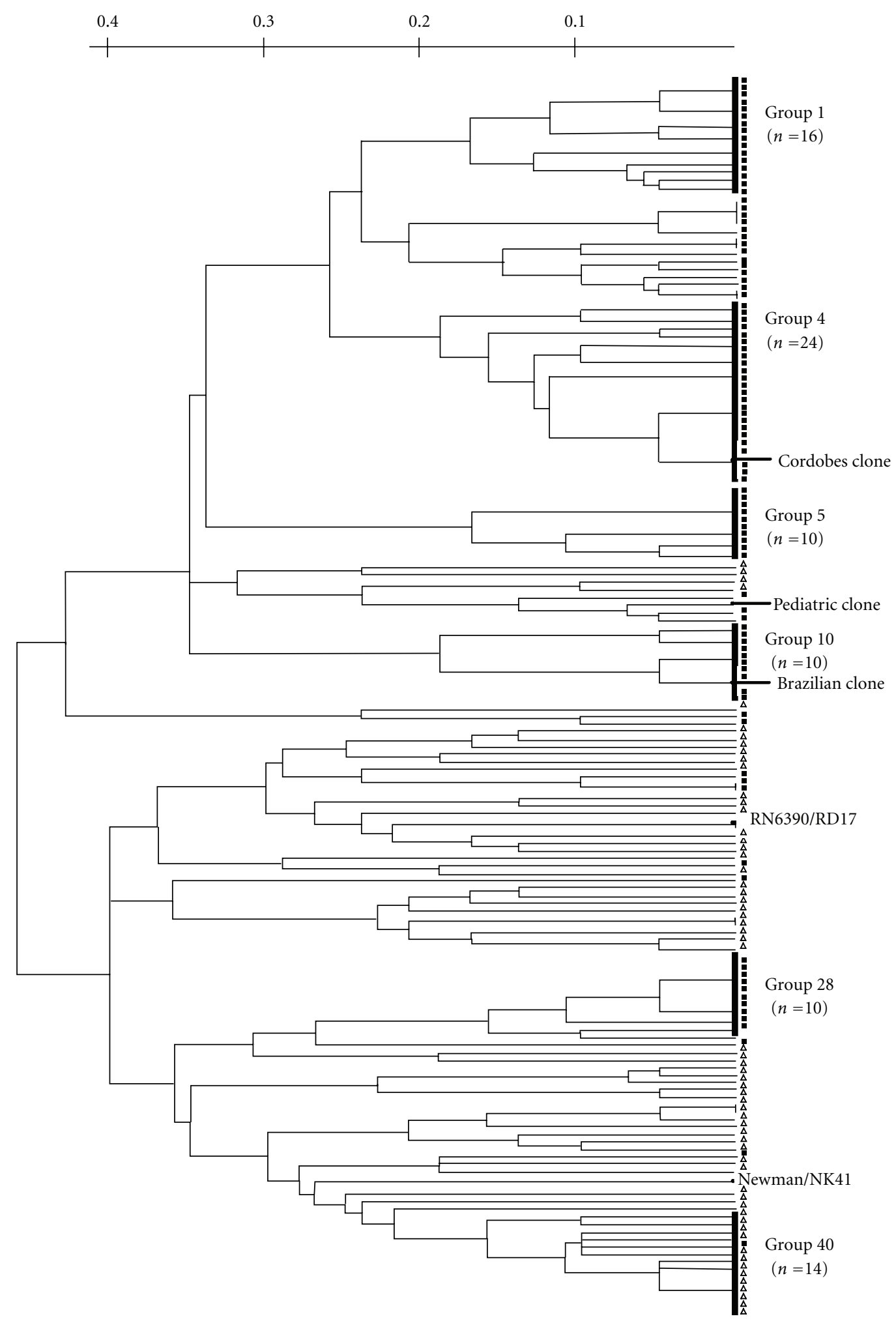

FIGURE 2: Dendrogram of S. aureus attenuated mutants (RD17 and NK41), their parental (RN6390 and Newman) strains, and S. aureus nasal colonizing $(\Delta)$ and osteomyelitis $(\mathbf{\square})(n=159)$ isolates. SmaI PFGE typing discriminated 40 different pulsotypes. The major groups were named 1, 4, 5, 10, 28, and 40. S. aureus strains representative of Cordobes, Pediatric, and Brazilian clones are indicated [26]. 
genotype when compared with those of nasal colonizing and osteomyelitis isolates (Figure 2). The number of genetic differences of the RD17 and NK41 mutant genomes (RN6390 and Newman background, resp.), compared with those $S$. aureus isolates was three or more, which made them clonally different according to the criteria set by Tenover et al. [27]. These results show that RD17 and NK41 mutants could be discriminated from osteomyelitis and nasal colonizing $S$. aureus isolates using SmaI macrorestriction PFGE typing.

\section{Discussion}

The disruption of the aroA gene that encodes for EPSPS enzyme leads to an auxotrophy in S. aureus for DHB, PABA, and aromatic amino acids. The inhibition of EPSPS results in shikimate accumulation, inhibition of synthesis of aromatic amino acids and secondary metabolites causing cell death [30]. We constructed previously S. aureus aroA mutants by transposon mutagenesis with Tn917 (FB306) and by insertion of the $\mathrm{Ka}^{R}$ gene into the aroA gene by allelic replacement mutagenesis (NK41). Both mutants were tested in two in vivo infection models with different purposes $[12,13]$. Recently, we demonstrated that the NK41 mutant interfered with the nasal colonization of clinical isolates of $S$. aureus representative of prevalent clones in Argentina. It is important to note that the FB306 and NK41 mutants have inserted in their genome an antibiotic resistance gene allowing their easy selection and in vitro identification. However, this feature is a disadvantage for its potential use in vertebrate. For this reason we constructed a $\triangle$ aroA mutant of S. aureus RN6390 strain by allelic exchange. The obtained mutant (RD17) failed to show any measurable reversion and remained attenuated in vivo.

In the present study, the nasal colonization of leukopenic mice represented a risk state for disseminated infections by S. aureus. In this model we observed that the MRSA Sa14 isolate multiplied in noses more easily due to decreased host defenses and this increase was statistical significance with respect to the control group $(P<0.001)$. In contrast, leukopenic animals challenged with the attenuated mutant RD17 showed similar levels of nasal colonization as the control animals group; therefore, the RD17 mutant was safe under the conditions studied. Indeed, the RD17 mutant maintained the low growth levels in the nose regardless of the immune status of animals.

On the other hand, it was of interest to differentiate laboratory strains and their mutants (RD17 and NK41) from $S$. aureus isolated from patients with osteomyelitis and nasal carriers. This information will be required for future studies. We performed SmaI PFGE typing because it is still the most discriminative of the available genotypic methods for S. aureus [31]. The analysis indicated that the RD17 and NK41 mutants were unequivocally discriminated from nasal colonizing and osteomyelitis $S$. aureus isolates under investigation. Moreover, both aroA mutants showed pulsotypes totally different to those observed for $S$. aureus representative of Brazilian, Cordobes, and Pediatric clones. A major concern to use an attenuated live mutant in vivo is the possibility that new cases of the disease may be caused by the revertant strain. The deletion of aroA gene described in this paper showed the stability of the RD17 mutant in mice and its inability to cause disseminated infections in leukopenic nasal colonized mice. Therefore, the spreading of spontaneous derivative RD17 mutants would be an unlikely event to occur.

In the last years emergence of mupirocin resistance among MRSA and MSSA isolates has been reported [32-36]. This is a worrying situation in addition to the emergence of multiresistant S. aureus strains [37-39]. Based on our results we postulate that aroA mutant of $S$. aureus could be utilized as an alternative strategy to reduce the staphylococcal nasal carriage.

\section{Acknowledgments}

This work was supported in part by grants from ANPCyT (PICT 06/00991 and PICT 10/0733) and Universidad de Buenos Aires (UBACYT 061), Buenos Aires, Argentina. The authors thank Ambrose L. Cheung (Darmouth Medical School, Hanover, New Hampshire) for providing plasmid pALC1743 and Michel Débarbouillé (Institut Pasteur, Centre National de la Recherche Scientifique, Paris) for providing plasmid pMAD. The authors wish to acknowledge the excellent technical assistance of Lorena Medina. They also thank the anonymous reviewers whose comments helped them to improve their manuscript.

\section{References}

[1] F. R. DeLeo and H. F. Chambers, "Reemergence of antibioticresistant Staphylococcus aureus in the genomics era," The Journal of Clinical Investigation, vol. 119, no. 9, pp. 2464-2474, 2009.

[2] F. D. Lowy, "Medical progress: Staphylococcus aureus infections," The New England Journal of Medicine, vol. 339, no. 8, pp. 520-532, 1998.

[3] A. van Belkum, D. C. Melles, J. Nouwen et al., "Co-evolutionary aspects of human colonisation and infection by Staphylococcus aureus," Infection, Genetics and Evolution, vol. 9, no. 1, pp. 32-47, 2009.

[4] C. Carbon, "Costs of treating infections caused by methicillinresistant staphylococci and vancomycin-resistant enterococci," Journal of Antimicrobial Chemotherapy, vol. 44, pp. 31-36, 1999.

[5] S. S. Huang and R. Platt, "Risk of methicillin-resistant Staphylococcus aureus infection after previous infection or colonization," Clinical Infectious Diseases, vol. 36, no. 3, pp. 281-285, 2003.

[6] S. S. Huang, D. J. Diekema, D. K. Warren et al., "Strain-relatedness of methicillin-resistant Staphylococcus aureus isolates recovered from patients with repeated infection," Clinical Infectious Diseases, vol. 46, no. 8, pp. 1241-1247, 2008.

[7] G. R. Donowitz, D. G. Maki, C. J. Crnich, P. G. Pappas, and K. V. Rolston, "Infections in the neutropenic patient-new views of an old problem," American Society of Hematology, pp. 113139, 2001.

[8] V. G. Fowler, J. M. Miro, B. Hoen et al., "Staphylococcus aureus endocarditis: a consequence of medical progress," JAMA, vol. 293, no. 24, pp. 3012-3021, 2005. 
[9] P. A. Pizzo, "Fever in immunocompromised patients," The New England Journal of Medicine, vol. 341, no. 12, pp. 893900, 1999.

[10] L. A. J. O’Neill, “Toll-like receptor signal transduction and the tailoring of innate immunity: a role for Mal?" Trends in Immunology, vol. 23, no. 6, pp. 296-300, 2002.

[11] P. Scapini, J. A. Lapinet-Vera, S. Gasperini, F. Calzetti, F. Bazzoni, and M. A. Cassatella, "The neutrophil as a cellular source of chemokines," Immunological Reviews, vol. 177, pp. 195-203, 2000.

[12] M. S. Barbagelata, L. Alvarez, M. Gordiola et al., "Auxotrophic mutant of Staphylococcus aureus interferes with nasal colonization by the wild type," Microbes and Infection, vol. 13, no. 1213, pp. 1081-1090, 2011.

[13] F. R. Buzzola, M. S. Barbagelata, R. L. Caccuri, and D. O. Sordelli, "Attenuation and persistence of and ability to induce protective immunity to a Staphylococcus aureusaroA mutant in mice," Infection and Immunity, vol. 74, no. 6, pp. 3498-3506, 2006.

[14] T. L. Bannerman, Staphylococcus, Micrococcus, and Other Catalase-Positive Cocci That Grow Aerobically, ASM Press, Washington, DC, USA, 2003.

[15] F. Martineau, F. J. Picard, P. H. Roy, M. Ouellette, and M. G. Bergeron, "Species-specific and ubiquitous-DNA-based assays for rapid identification of Staphylococcus aureus," Journal of Clinical Microbiology, vol. 36, no. 3, pp. 618-623, 1998.

[16] Performance Standards for Antimicrobial Disk Susceptibility Tests; Approved Standard, Clinical and Laboratory Standards Institute, 2006.

[17] P. D. Fey, B. Saï-Salim, M. E. Rupp et al., "Comparative molecular analysis of community- or hospital-acquired methicillin-resistant Staphylococcus aureus," Antimicrobial Agents and Chemotherapy, vol. 47, no. 1, pp. 196-203, 2003.

[18] P. A. Pattee and D. S. Neveln, "Transformation analysis of three linkage groups in Staphylococcus aureus," Journal of Bacterio$\log y$, vol. 124, no. 1, pp. 201-211, 1975.

[19] M. Arnaud, A. Chastanet, and M. Débarbouillé, "New vector for efficient allelic replacement in naturally nontransformable, low-GC-content, gram-positive bacteria," Applied and Environmental Microbiology, vol. 70, no. 11, pp. 6887-6891, 2004.

[20] J. Valle, A. Toledo-Arana, C. Berasain et al., "SarA and not $\sigma \mathrm{B}$ is essential for biofilm development by Staphylococcus aureus," Molecular Microbiology, vol. 48, no. 4, pp. 1075-1087, 2003.

[21] B. C. Kahl, M. Goulian, W. Van Wamel et al., "Staphylococcus aureus RN6390 replicates and induces apoptosis in a pulmonary epithelial cell line," Infection and Immunity, vol. 68, no. 9, pp. 5385-5392, 2000.

[22] National, Research, and Council, in Book Guide for the Care and Use of Laboratory Animals (NIH guide, revised), National Academy Press, Washington, DC, USA, 1996.

[23] J. M. Mei, F. Nourbakhsh, C. W. Ford, and D. W. Holden, "Identification of Staphylococcus auerus virulence genes in a murine model of bacteraemia using signature-tagged mutagenesis," Molecular Microbiology, vol. 26, no. 2, pp. 399-407, 1997.

[24] D. Finney, Probit Analysis, Cambrige University Press, London, UK, 1971.

[25] W. A. Craig, J. Redington, and S. C. Ebert, "Pharmacodynamics of amikacin in vitro and in mouse thigh and lung infections," Journal of Antimicrobial Chemotherapy, vol. 27, pp. 2940, 1991.

[26] S. M. Lattar, L. P. N. Tuchscherr, D. Centrón et al., "Molecular fingerprinting of Staphylococcus aureus isolated from patients with osteomyelitis in Argentina and clonal distribution of the cap5(8) genes and of other selected virulence genes," European Journal of Clinical Microbiology and Infectious Diseases. In press.

[27] F. C. Tenover, R. Arbeit, G. Archer et al., "Comparison of traditional and molecular methods of typing isolates of Staphylococcus aureus," Journal of Clinical Microbiology, vol. 32, no. 2, pp. 407-415, 1994.

[28] L. S. Quelle, A. Corso, M. Galas, and D. O. Sordelli, "STAR gene restriction profile analysis in epidemiological typing of methicillin-resistant Staphylococcus aureus: description of the new method and comparison with other polymerase chain reaction (PCR)-based methods," Diagnostic Microbiology and Infectious Disease, vol. 47, no. 3, pp. 455-464, 2003.

[29] Y. Van De Peer and R. De Wachter, “Treecon for windows: a software package for the construction and drawing of evolutionary trees for the microsoft windows environment," Bioinformatics, vol. 10, no. 5, pp. 569-570, 1994.

[30] F. J. L. Aragão and A. C. M. Brasileiro, "Positive, negative and marker-free strategies for transgenic plant selection," Brasilian Journal of Plant Physiology, vol. 14, no. 1, pp. 1-10, 2002.

[31] A. Strandén, R. Frei, and A. F. Widmer, "Molecular typing of methicillin-resistant Staphylococcus aureus: can PCR replace pulsed-field gel electrophoresis?" Journal of Clinical Microbiology, vol. 41, no. 7, pp. 3181-3186, 2003.

[32] E. S. Walker, J. E. Vasquez, R. Dula, H. Bullock, and F. A. Sarubbi, "Mupirocin-resistant, methicillin-resistant Staphylococcus aureus: does mupirocin remain effective?" Infection Control and Hospital Epidemiology, vol. 24, no. 5, pp. 342-346, 2003.

[33] A. E. Simor, T. L. Stuart, L. Louie et al., "Mupirocin-resistant, methicillin-resistant Staphylococcus aureus strains in Canadian Hospitals," Antimicrobial Agents and Chemotherapy, vol. 51, no. 11, pp. 3880-3886, 2007.

[34] J. E. Vasquez, E. S. Walker, B. W. Franzus, B. K. Overbay, D. R. Reagan, and F. A. Sarubbi, "The epidemiology of mupirocin resistance among methicillin-resistant Staphylococcus aureus at a Veterans' Affairs hospital," Infection Control and Hospital Epidemiology, vol. 21, no. 7, pp. 459-464, 2000.

[35] J. C. Jones, T. J. Rogers, P. Brookmeyer et al., "Mupirocin resistance in patients colonized with methicillin-resistant Staphylococcus aureus in a surgical intensive care unit," Clinical Infectious Diseases, vol. 45, no. 5, pp. 541-547, 2007.

[36] B. D. Cookson, "The emergence of mupirocin resistance: a challenge to infection control and antibiotic prescribing practice," Journal of Antimicrobial Chemotherapy, vol. 41, no. 1, pp. 11-18, 1998.

[37] S. A. Boers, I. Van Ess, S. M. Euser, R. Jansen, F. R. H. Tempelman, and B. M. W. Diederen, "An outbreak of a Multiresistant Methicillin-Susceptible Staphylococcus aureus (MRMSSA) strain in a Burn Centre: the importance of routine molecular typing," Burns, vol. 37, no. 5, pp. 808-813, 2011.

[38] E. Nannini, B. E. Murray, and C. A. Arias, "Resistance or decreased susceptibility to glycopeptides, daptomycin, and linezolid in methicillin-resistant Staphylococcus aureus," Current Opinion in Pharmacology, vol. 10, no. 5, pp. 516-521, 2010.

[39] C. Sola, R. O. Lamberghini, M. Ciarlantini et al., "Heterogeneous vancomycin-intermediate susceptibility in a community-associated methicillin-resistant Staphylococcus aureus epidemic clone, in a case of Infective Endocarditis in Argentina," Annals of Clinical Microbiology and Antimicrobials, vol. 10, article 15, 2011. 

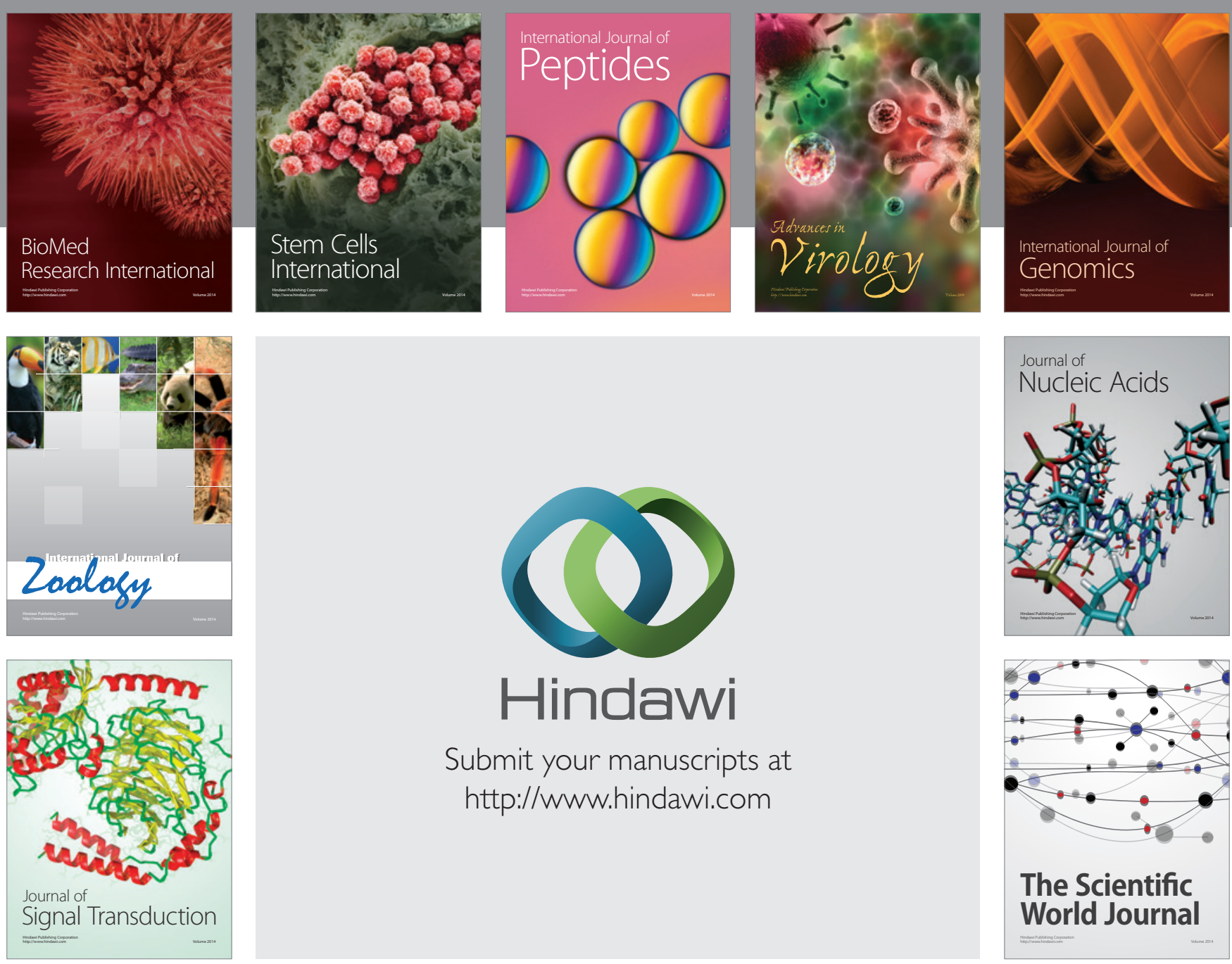

Submit your manuscripts at

http://www.hindawi.com
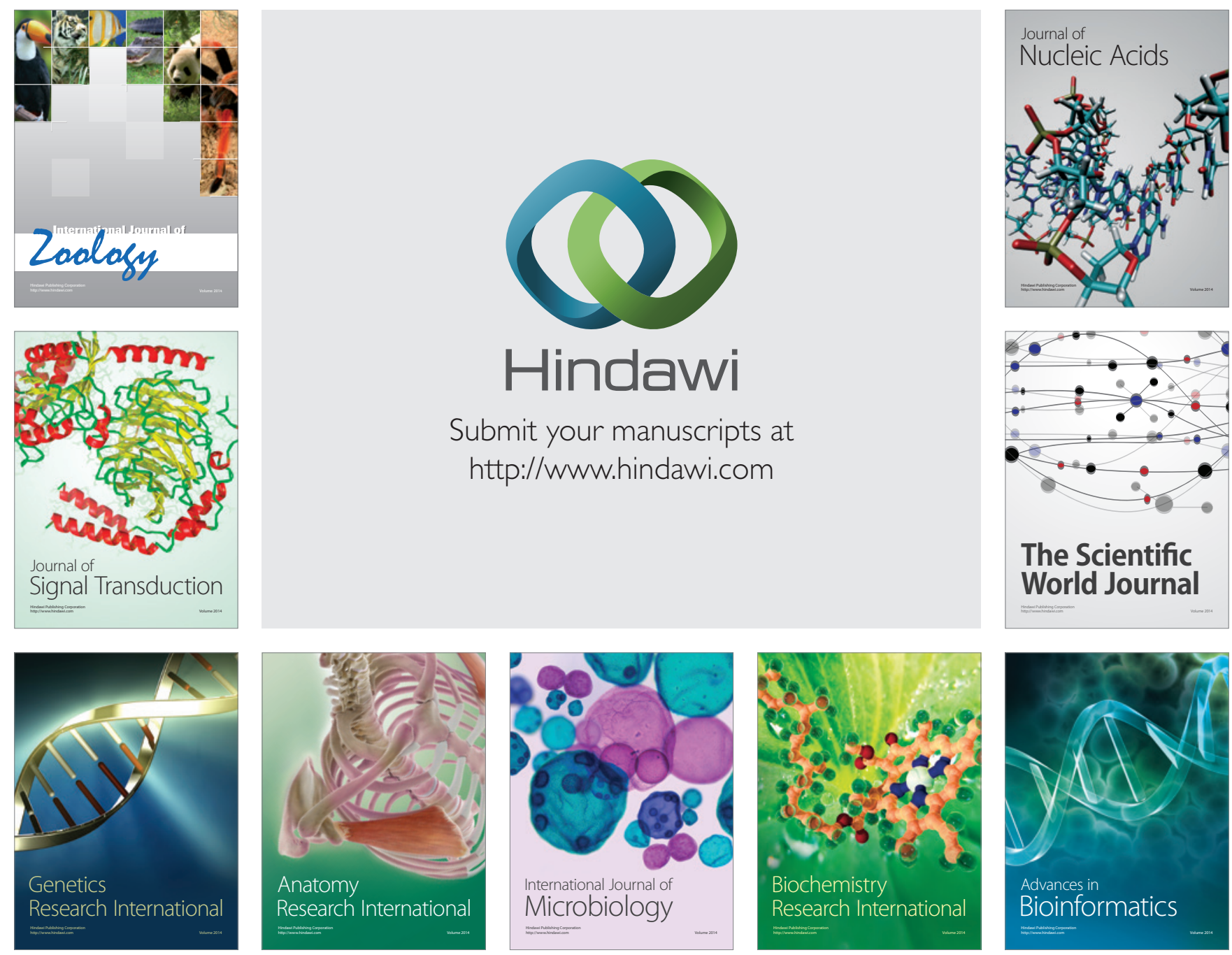

The Scientific World Journal
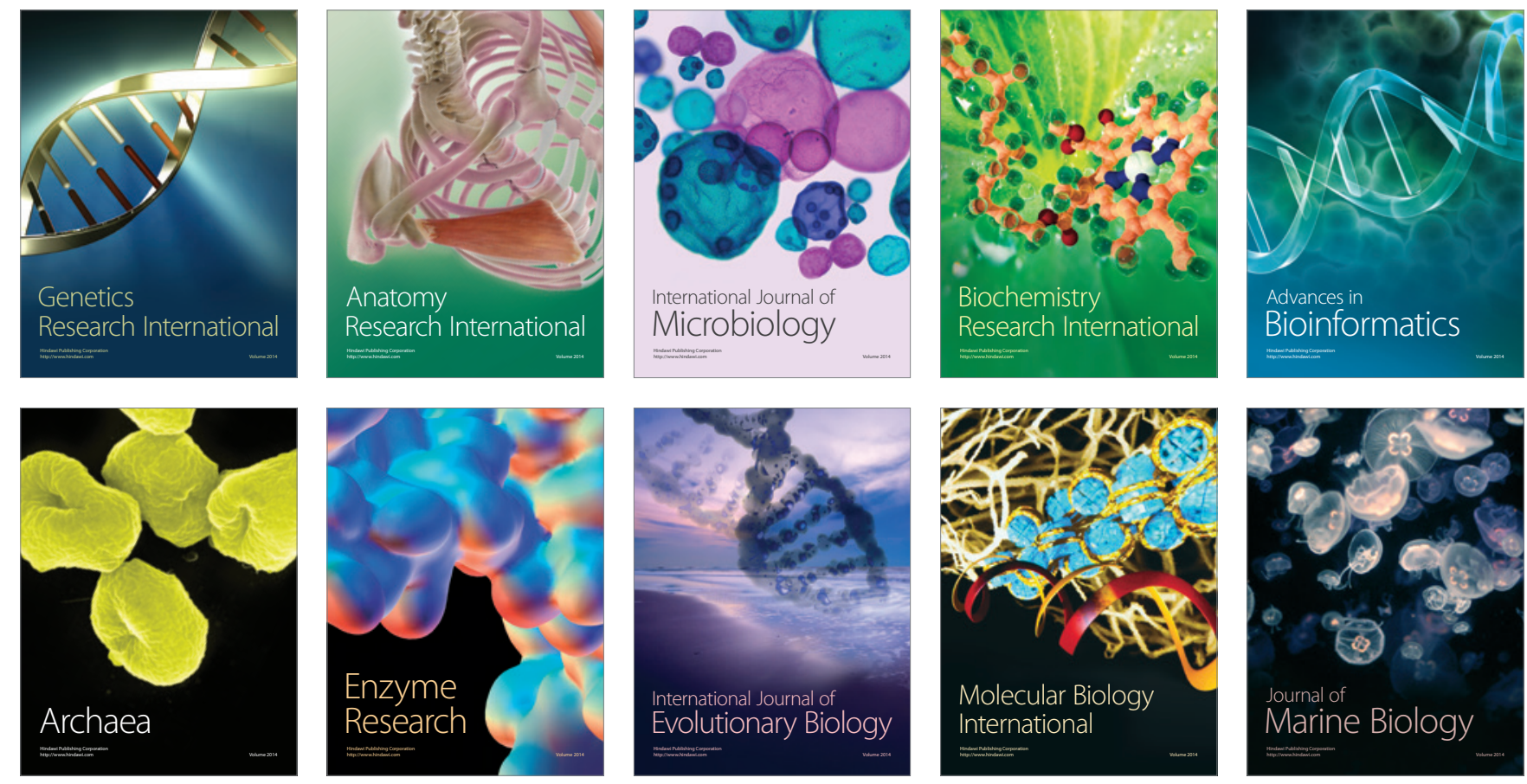